\title{
PERFORMANCE OF CHARM-F - THE AIRBORNE DEMONSTRATOR FOR MERLIN
}

\author{
Axel Amediek ${ }^{1 *}$, Gerhard Ehret ${ }^{1}$, Andreas Fix ${ }^{1}$, Martin Wirth ${ }^{1}$, Christian Büdenbender ${ }^{1}$, Mathieu \\ Quatrevalet $^{1}$, Christoph Kiemle ${ }^{1}$ \\ ${ }^{I}$ Deutsches Zentrum für Luft- und Raumfahrt (DLR) Oberpfaffenhofen, Germany \\ *axel.amediek@dlr.de
}

\begin{abstract}
In 2015, the new airborne lidar CHARM-F for the measurement of the greenhouse gases carbon dioxide and methane was set into operation. It is an integrated path differential absorption (IPDA) lidar designed for the use onboard the German research aircraft HALO. Due to its high technological similarity to the MERLIN space lidar, it is also a demonstrator for the space system. Here, we report on CHARM-F's technology, the experiences with the IPDA lidar method and the achieved performance.
\end{abstract}

\section{INTRODUCTION}

Better understanding of the carbon fluxes in the Earth's atmosphere is a current research issue. This topic is of particular importance, because carbon dioxide $\left(\mathrm{CO}_{2}\right)$ and methane $\left(\mathrm{CH}_{4}\right)$ are the two most relevant anthropogenic greenhouse gases contributing to global radiative forcing. The concentrations of both gases have significantly increased since the beginning of the industrial era $\left(\mathrm{CO}_{2}\right.$ from $280 \mathrm{ppm}$ to $400 \mathrm{ppm}$ and $\mathrm{CH}_{4}$ from about $700 \mathrm{ppb}$ to $1847 \mathrm{ppb}$ ). There is still a lack of knowledge related to sources and sinks, which limits the accuracy of climate change projections.

Active remote sensing has the potential to close the gaps. The integrated path differential absorption (IPDA) lidar technique can reach the stringent requirements to be met for significant contribution here. The aim is to generate high resolved data of $\mathrm{CO}_{2}$ and $\mathrm{CH}_{4}$ gradients to be used as inputs for inverse modeling.

CHARM-F $\left(\mathrm{CO}_{2}\right.$ and $\mathrm{CH}_{4}$ atmospheric remote monitoring - Flugzeug) is an IPDA lidar for the simultaneous measurement of $\mathrm{CO}_{2}$ and $\mathrm{CH}_{4}$, designed for operation onboard the German research aircraft HALO (high altitude and long range research aircraft). Its purpose is to quantify concentration gradients and surface fluxes of $\mathrm{CO}_{2}$ and $\mathrm{CH}_{4}$, both, over point sources and large-scale sources.

Due to the high technological similarity, it is an airborne demonstrator for the French-German satellite mission MERLIN (methane remote sensing lidar mission), which recently has entered its project phase C. Furthermore, it is planned to use CHARM-F for the validation of future MERLIN data.

In 2015, CHARM-F was flown for the first time during a test campaign. For spring 2017, the first scientific campaign CoMet [1] is planned.

\section{THE IPDA LIDAR PRINCIPLE}

The key factor of the IPDA method is the fact that the strong laser light backscatter from a defined surface is measured instead of the atmospheric backscatter as in case of classical DIAL systems (see Figure 1). This surface is called "hard target" and can be the ground, the sea surface or a sharply edged cloud surface. The reasons are the comparatively weak atmospheric backscatter in the $1.6 \mu \mathrm{m}$ wavelength region, which is on the other hand favorable for the measurement of $\mathrm{CO}_{2}$ and $\mathrm{CH}_{4}$, and the required high measurement precision to resolve the existent concentration variations of these gases. The derived quantity is the column-averaged dry-air mixing ratio of the trace gas Xgas [2]:

$$
X g a s=\frac{D A O D}{\int_{p_{-} \text {aircr }}^{p_{-} \operatorname{targ} e t} W F(p, T) \cdot d p}
$$

The differential absorption optical depth $D A O D$ is calculated from the measured signals $S^{\text {target }}$ (hard 
target backscatter) and $E^{\text {ref }}$ (the energy reference inside the instrument) for online and offline:

$$
D A O D=\frac{1}{2} \cdot \ln \frac{S_{o f}^{t \text { arget }} / E_{o f f}^{r e f}}{S_{o n}^{t a r g e t} / E_{o n}^{r e f}}
$$

The weighting function $W F$ is integrated in (1) from the hard target to the aircraft (here expressed in pressure coordinates). It is calculated as follows:

$$
W F(p, T)=\frac{\sigma_{o n}(p, T)-\sigma_{o f f}(p, T)}{g \cdot\left(m_{d r y-a i r}+m_{H_{2} O} \cdot q_{H_{2} O}\right)}
$$

using the absorption cross sections $\sigma$ for online and offline, the normal gravity $g$ and the molecular masses $m_{d r y-a i r}$ of an average dry-air molecule and $m_{\mathrm{H} 2 \mathrm{O}}$ of a water molecule, with $q_{\mathrm{H} 2 \mathrm{O}}$ as the dry-air volume mixing ratio of water vapor.

For calculating $W F$, external data are required, such as the temperature $T$, the pressure $p$ and $q_{\mathrm{H} 2 \mathrm{O}}$ along the column (e.g. from numerical weather prediction like ECMWF) as well as spectroscopic data for $\sigma$ (e.g. from databases like HITRAN).

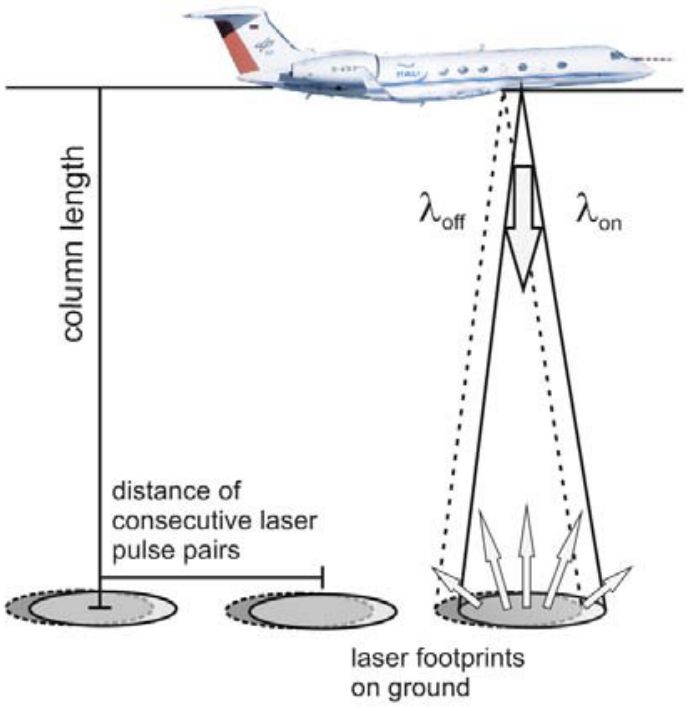

Figure 1. CHARM-F's measurement principle: Laser double pulses (online and offline) are emitted and backscattered by the ground (or cloud tops or the sea surface)

The instrument CHARM-F operates with short laser double pulses (20 ns each with $500 \mu$ s separation at $50 \mathrm{~Hz}$ ), which leads to a precise ranging capability and high SNRs for each single shot measurement. Due to the double pulses, the illuminated spots on ground are almost identical for the online and offline measurements, which minimizes the impact of variable ground reflectivities. Main instrument specifications are listed in Table (1). The instrument, installed in the aircraft, is shown in Figure 2.

Table 1. CHARM-F system specifications

\begin{tabular}{|l|l|}
\hline Parameter & Value \\
\hline Lidar type & $\begin{array}{l}\text { Integrated path differential } \\
\text { absorption (IPDA) lidar } \\
\text { using 2 wavelengths (online } \\
\text { and offline) per trace gas }\end{array}$ \\
\hline $\begin{array}{l}\text { Receiving } \\
\text { method }\end{array}$ & direct detection \\
\hline $\begin{array}{l}\text { Measured trace } \\
\text { gases }\end{array}$ & $\begin{array}{l}\text { atmospheric } \mathrm{CO}_{2} \text { and } \mathrm{CH}_{4} \\
\text { (column averaged dry-air } \\
\text { mixing ratios) }\end{array}$ \\
\hline Laser type & Nd:YAG pumped OPOs \\
\hline $\begin{array}{l}\text { Laser } \\
\text { specifications }\end{array}$ & $\begin{array}{l}10 \mathrm{~mJ} \text { pulse energies, } \\
50 \mathrm{~Hz} \text { double pulses (500 } \mu \mathrm{s} \\
\text { pulse separation), 20 ns pulse } \\
\text { width }\end{array}$ \\
\hline Wavelengths & $\begin{array}{l}1572 \mathrm{~nm}\left(\mathrm{CO}_{2}\right) \\
1646 \mathrm{~nm}\left(\mathrm{CH}_{4}\right)\end{array}$ \\
\hline Detector types & InGaAs $\mathrm{PINs}_{\text {and }} \mathrm{APDs}^{2}$ \\
\hline $\begin{array}{l}\text { Reference gas } \\
\text { cell }\end{array}$ & $\begin{array}{l}36 \text {-m multipass, } \mathrm{CO}_{2} \text { and } \mathrm{CH}_{4} \\
\text { filled }\end{array}$ \\
\hline
\end{tabular}

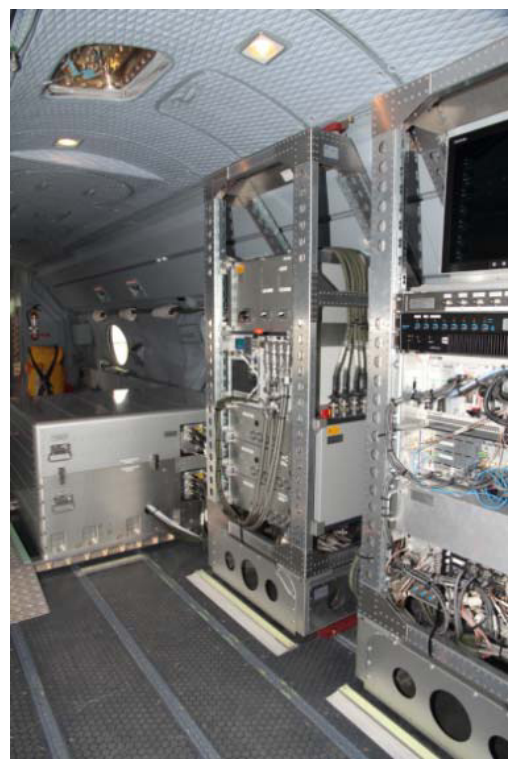

Figure 2. CHARM-F system installed in HALO 


\section{RESULTS}

In the following, important results of the 2015 test flight campaign are presented.

\subsection{System performance}

One key objective of the instrument is to achieve a high measurement precision (low statistical noise) to resolve small gradients in the trace gas concentrations. The results of the first flight campaign were analyzed to that effect. Figure 3 $\left(\mathrm{CO}_{2}\right)$ and Figure $4\left(\mathrm{CH}_{4}\right)$ show the decreasing of the mixing ratio standard deviations along with averaging.

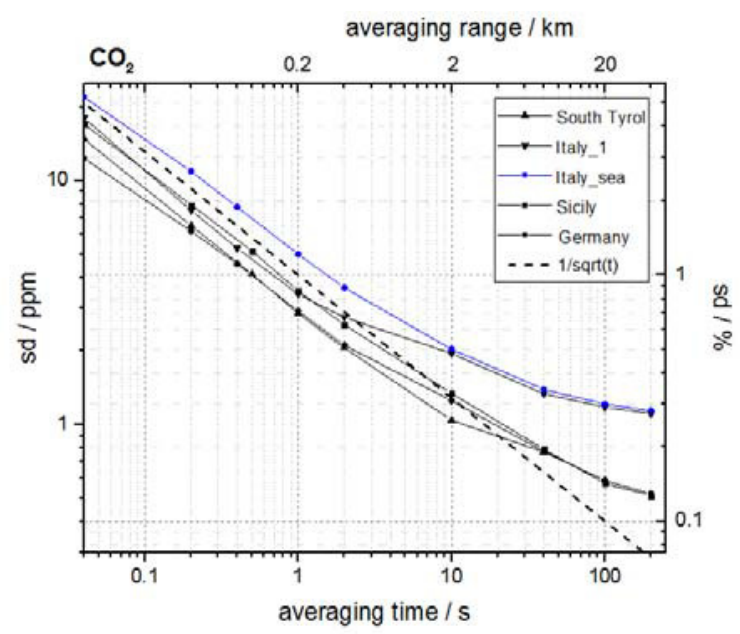

Figure 3. Noise statistics for $\mathrm{CO}_{2}$ measurements from different flight legs along with data averaging.

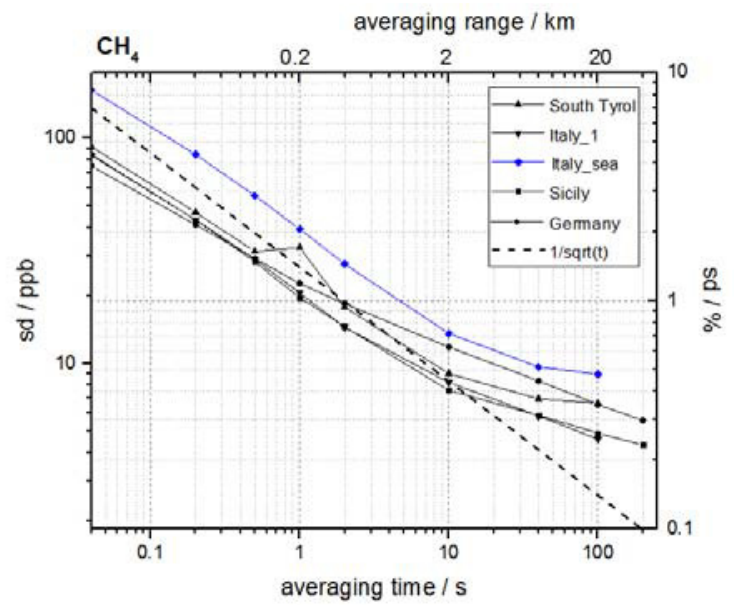

Figure 4. Noise statistics for $\mathrm{CH}_{4}$ measurements from different flight legs along with data averaging.
Each figure contains plots from different regions including the sea surface. It is shown that during the test flights a precision of below $1 \%$ was reached after few seconds of averaging and after $100 \mathrm{~s}$ (i.e. $20 \mathrm{~km}$ horizontal averaging) a mixing ratio precision of below $0.3 \%\left(\mathrm{CO}_{2}\right)$ and $0.5 \%$ $\left(\mathrm{CH}_{4}\right)$.

The use of laser double pulses reduces the "reflectivity noise" effectively, which occurs if the ground reflectivity for online and offline laser footprints varies. This is a special challenge resulting from the IPDA lidar approach. However, due to the short distance (in time and space) between online and offline measurements, the impact of these unavoidable reflectivity variations is minimized for the CHARM-F system. This is clearly shown by the flight measurements.

The absolute values retrieved from the measurements show offsets, if in-situ profile measurements are taken as a basis for comparisons, which were obtained by an onboard cavity ring down spectrometer [3] during the campaign. These offsets can be partly explained by beam misalignments. The reasons and possible improvements are currently under investigation. This issue has to be resolved before the next flights. In case of $\mathrm{CH}_{4}$ another reason could play a decisive role: The accuracy of the spectroscopic parameters in combination with the applied absorption line shape model for the calculation of the absorption cross sections, as used in Eq. (3). It is possible that the calculated cross section for online (within a "trough" formed by the overlay of six methane absorption lines) is imprecise. Studies using different data and models are in progress.

\subsection{Broken clouds}

A major advantage of active remote sensing of trace gases from aircraft or satellite is the ability to retrieve meaningful data even under conditions of broken clouds, since lidars operate with small and defined footprints compared to passive sensors. The CHARM-F aircraft measurements demonstrate that the separation of clouds and ground can be done easily shot-by-shot using the ranging information. The Figure 5 and Figure 6 show the alternating $D A O D$ s for clouds and ground, as expected. This allows also the retrieval of column parts, e.g. mixing ratio values for the boundary layer separated from the whole column. 


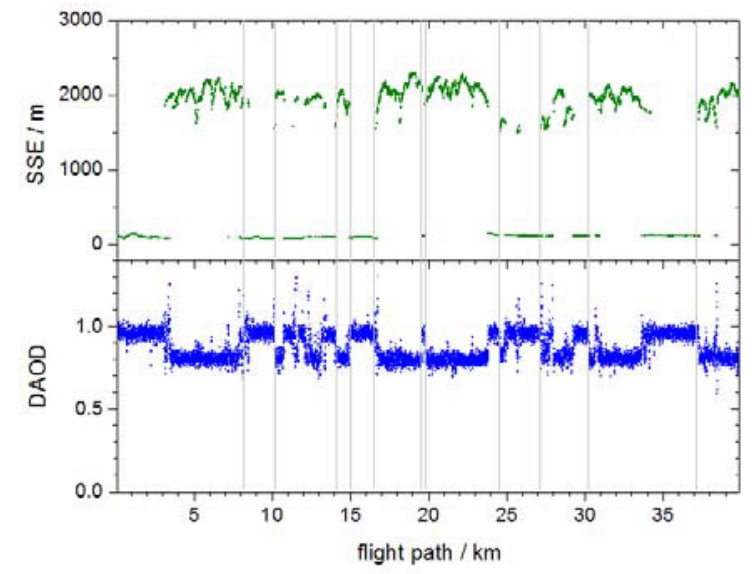

Figure 5. DAOD single-shot measurements of $\mathrm{CO}_{2}$ for a broken cloud scenery. Cloud tops and the ground can be distinguished by the SSE levels (surface scattering elevation)

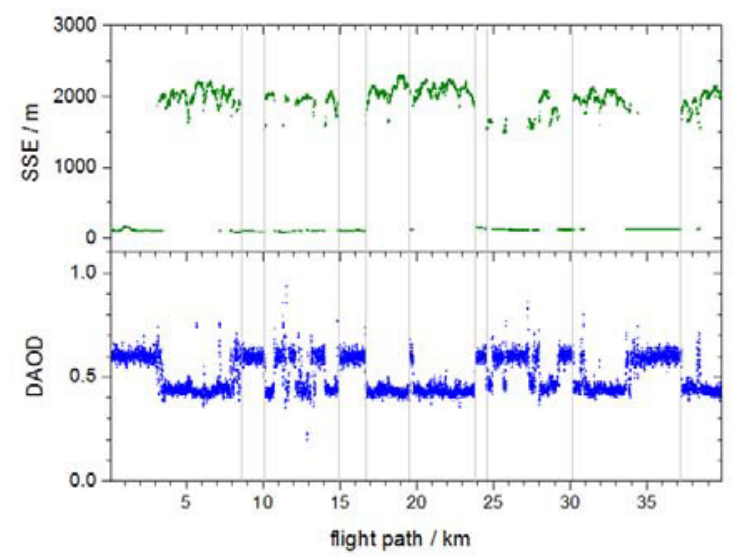

Figure 6. DAOD single-shot measurements of $\mathrm{CH}_{4}$ for a broken cloud scenery (the same track section as shown in Figure 5).

\subsection{Point source emissions}

During the test flight campaign, known strong point sources of $\mathrm{CO}_{2}$ and $\mathrm{CH}_{4}$ were overflown. In one case a $\mathrm{CH}_{4}$ plume from a hard coal mine ventilation shaft could be identified and for $\mathrm{CO}_{2}$, the plume of a huge coal fired power plant was detected.

By means of the Gaussian plume approximation and the budget approach, the emission rates of the point sources were estimated. They agree well with reported numbers. For more information, see the paper presented by Ehret et al. [4].

\section{CONCLUSIONS}

The first flight measurements using CHARM-F on the German research aircraft HALO show promising results. The IPDA-lidar approach using two wavelengths (online and offline) emitted as laser double pulses with short separation allows high measurement precisions of less than $0.5 \%$ for $100 \mathrm{~s}$ averages (i.e. $20 \mathrm{~km}$ horizontal averaging).

However, shortcomings with respect to the absolute accuracy of the retrieved mixing ratios were found when the results were compared to independent data. Probably laser beam misalignments partly cause the deviations. Additionally, the spectroscopic modelling of the trace gas absorption could cause offsets.

The capability to handle broken cloud conditions was demonstrated.

The crossings of $\mathrm{CH}_{4}$ and $\mathrm{CO}_{2}$ plumes, emitted by strong point sources were clearly detectable in the DAODs. Estimations of the emission rates using these data resulted in reasonable values compared to reported data.

For spring 2017 the first scientific aircraft measurement campaign "CoMet" with CHARM-F on HALO is planned.

\section{References}

[1] Fix, A., Amediek, A., Bovensmann, H., Ehret, G., Gerbig, C., Gerilowski, K., Pfleilsticker, K., Roiger, A., Zöger, M., 2017: CoMet: An airborne mission to simultaneously measure $\mathrm{CO}_{2}$ and $\mathrm{CH}_{4}$ using lidar, passive remote sensing, and in-situ techniques, Proceedings of the 28th International Laser Radar Conference (ILRC 28)

[2] Ehret, G., Kiemle, C., Wirth, M., Amediek, A., Fix, A., Houweling, S., 2008: Space-borne remote sensing of $\mathrm{CO}_{2}, \mathrm{CH}_{4}$, and $\mathrm{N}_{2} \mathrm{O}$ by integrated path differential absorption lidar: a sensitivity analysis, Applied Physics B, 90(3-4), 593-608.

[3] Filges, A., Gerbig, C., Chen, H., Franke, H., Klaus, C. and Jordan, A., 2015: The IAGOS-core greenhouse gas package: a measurement system for continuous airborne observations of $\mathrm{CO}_{2}, \mathrm{CH}_{4}, \mathrm{H}_{2} \mathrm{O}$ and $\mathrm{CO}$, Tellus B, 67(0)

[4] Ehret, G., Amediek, A., Wirth, M., Fix, A., Quatrevalet, M., 2017: Quantification of greenhouse gas emission of strong point sources by airborne IPDAlidar measure-ments, Proceedings of the 28th International Laser Radar Conference (ILRC 28) 